\title{
Marga Clark la última Roësset. Arte a través del tiempo y de las fronteras.
}

\section{Marga Clark the last Roësset. Art across time and borders.}

TIPO DE TRABAJO:

Comunicación virtual.

PALABRAS CLAVE:

Poesía, Fotografía, Arte Global.

KEY WORDS:

Poetry, photography, Global Art.

\section{RESUMEN.}

La artista Marga Clark, última descendiente de la saga familiar Roësset, donde destacan las artistas femeninas, es una poeta y artista fotógrafa que combina ambas disciplinas en su obra, la misma, destaca por un lirismo único, que traspasa fronteras y unifica sentimientos en un mundo globalizado. Resultando ser un claro exponente de la plástica artística actual. En la comunicación que propongo, pretendo realizar un recorrido por sus cuarenta años de trayectoria profesional y sus tres etapas más destacadas, analizando la evolución de su realización artística. Marga Clark ha publicado varios libros de sus obras, el primero de ellos, Static Movement/Movimiento Estático, fue adquirido por el MOMA de Nueva York con el fin de ser vendido en su librería. En 1991 publica Impresiones Fotográficas, un libro de ensayo sobre el lenguaje fotográfico. Esta artista colabora con diversos medios de comunicación desde la década de los 80 , como reportera gráfica. Entre ellos, La Vanguardia y El País. A lo largo de su carrera ha expuesto su obra fotográfica en numerosas exposiciones, tanto individuales como colectivas, en América y en Europa. Actualmente, se puede apreciar su exposición retrospectiva Marga Clark, Cosmogonía (1976-2016) en la Fundación Antonio Pérez y en el Museo de la Fotografía de Huete, Cuenca. Por otro lado, cabe destacar que su obra se puede encontrar de modo permanente en colecciones como la del Museo de Brooklyn de Nueva York, la Biblioteca Nacional de Paris, el Museo Español de Arte Contemporáneo de Madrid, la Col.lecció Testimoni de la Caixa de Barcelona, la Sociedad Estatal para Exposiciones Internacionales, la Fundación Telefónica o la Colección Helga de Alvear, entre otras. Se puede decir que esta fotógrafa-poeta destaca por su obra, a la vez que unifica de manera magistral fotografía y poesía.

\section{ABSTRACT.}

The artist Marga Clark, the last descendant of the family Roësset, where female artists stand out, is a poet and photographer who combine both disciplines in her work, it stands out for a unique lyricism that transcends boundaries and unifies feelings in a world Globalized. She is a clear exponent of current artistic art. In the communication that I propose, I intend to make a journey through his forty years of professional career and his three most outstanding stages, analyzing the evolution of his artistic achievement. Marga Clark has published several books of his works, the first of them, Static Movement / Static Movement, was acquired by the MOMA of New York in order to be sold in its bookstore. In 1991 publishes Photographic Impressions, a book essay on the photographic language. This artist has collaborated with various media since the 80's as a graphic reporter, including La Vanguardia or El País. Throughout his career he has exhibited his photographic work in numerous exhibitions, both individual and collective in America and Europe. His retrospective exhibition Marga Clark, Cosmology (1976-2016) at the Antonio Pérez Foundation, and at the Museum of Photography in 
Huete, Cuenca can be seen at the moment. On the other hand, it is possible to emphasize that his work can be found permanently in collections such as the Brooklyn Museum of New York, the National Library of Paris, the Spanish Museum of Contemporary Art in Madrid, Col.lecció Testimoni de la Caixa Of Barcelona, the State Society for International Exhibitions, the Telefónica Foundation or the Helga de Alvear Collection, among others. It can be said that this photographer-poet stands out for his work, while uniting masterfully photography and poetry.

\section{CONTENIDO.}

En este trabajo se pretende dar voz a la obra de la artista Marga Clark, poeta y fotógrafa, con una trayectoria a sus espaldas de cuarenta años de labor artística en los cuales sus trabajos han evolucionado de una forma única y magistral. En el año 2016 hemos podido asistir a la exposición de su antología en Fundación Antonio Pérez (Cuenca) y en el Museo de la Fotografía Fundación Antonio Pérez (Huete), una exposición magnífica que reúne estos cuarenta años de creatividad y realización notables.

Marga Clark desciende de una estirpe de mujeres artistas, la familia Roësset cuenta en su haber con varias artistas femeninas en diversos campos artísticos, esta genealogía femenina destaca por su talento. Desde la pintura, la escultura, la literatura a la fotografía, son varias las disciplinas artísticas que han trabajado y en las cuales han destacado.

Las artistas que antecedieron a nuestra creadora, fueron cuatro mujeres que destacaron en diferentes disciplinas y ámbitos artísticos. Estas son: La pintora María Roësset Mosquera, que firmaba sus obras como MaRo; Marisa Roësset y Velasco, que también fue pintora; Consuelo Gil Roëssset, escritora precoz, pedagoga y más tarde editora; y por último Marga Gil Roësset, considerada una niña prodigio, que ilustró los cuentos que escribía su hermana Consuelo Gil Roësset y que más tarde destacó como una brillante escultora. Es obvio el talento que esta familia de artistas mujeres poseía y que Marga Clark ha heredado.

De este modo, la escritora y fotógrafa madrileña, nos dice que su trabajo, es una forma de cuestionarse a sí misma y de adentrarse más en todo lo que le rodea ${ }^{1}$. Su obra se basa en un continuo cuestionamiento de la propia existencia de la artista y del mundo que le rodea. Cosmogonía, la exposición que reúne los cuarenta años de su obra, nos presenta este planteamiento de la autora a lo largo de toda su carrera, tanto de su faceta como fotógrafa, como de artista visual.

Tres son las épocas que marcan su carrera, pero aunque estén bien diferenciadas, en el fondo podemos observar una continuidad lírica a través de toda su obra, se aprecia en todas un sentido de la trascendencia que impregna y que no abandona ninguna de las obras de Marga Clark.

Estas tres etapas son: la primera Movimiento Estático que comprende el periodo que va de 1976 a 1985 , la segunda que lleva por nombre Transformaciones y que realizó de 1985 a 1988 y la tercera y última titulada: Instantáneas del alma, ejecutada entre los años 1988 y 2016.

Marga Clark fue becada entre los años 1963 y 1965 con la beca Margaret CAGE, para finalizar sus estudios universitarios en Bennet College, Millbrook, Nueva York y, más tarde, continuar sus estudios especializados en cine, teatro y fotografía en el Hunter College y en el Centro Internacional de Fotografía. Su primer libro de fotografías: Movimiento Estático (1976-1985) reúne sus primeras obras. Durante los años 70, a la vez que es la fotógrafa oficial de la Oficina Española de Turismo en Nueva York, Marga Clark comienza a fotografiar todo lo que le rodea y estudia Psicología del retrato con el gran maestro y retratista Philippe Halsman. Durante estos años realiza una serie de obras excelentes, que muestran en sucesión, los graduales cambios que se producen en una imagen, como en la serie titulada Nueva York de 1981 y que vemos abajo

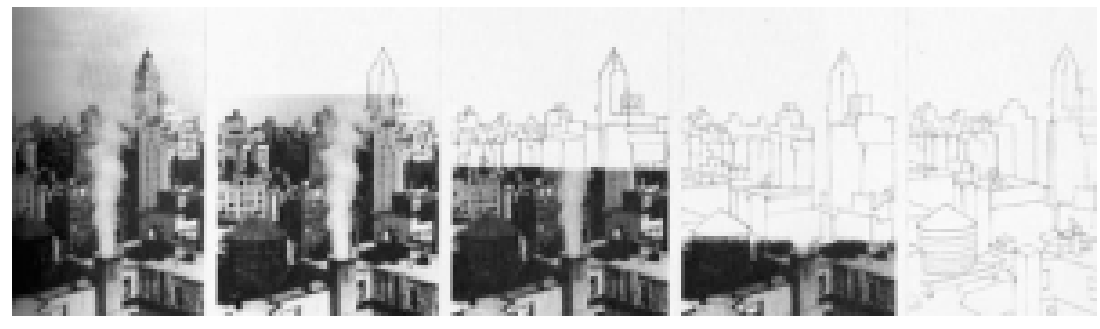

Nueva York, 1981.

\footnotetext{
${ }^{1}$ CLARK, Marga. Entrevista personal realizada el 20 enero de 2017, Madrid.
} 
En esta serie de fotografías, podemos ver una imagen típica del Nueva York de la década de los 80 . Es en cierto modo, una serie que nos muestra un paisaje urbano, que a través de la secuencia encadenada de imágenes, se va desdibujando, difuminando, convirtiéndose en un boceto inacabado de la ciudad, es una nueva forma de ver la imagen, un nuevo modo de entender el sustrato de la ciudad, lo que nos susurra la imagen, su esencia, donde todo se centra en el espacio, el tiempo, la forma.

Sobre esta serie Román Gubern nos dice:

"Toda una tradición de la vanguardia alemana de los años veinte, interna o periférica a la Bahaus, es reelaborada por el geometrismo de las series fotográficas de Marga Clark, madrileña de origen, pero residente en Nueva York, de cuya verticalidad de hormigón, de vidrio y de acero tantos estímulos gráficos ha extraído su cámara" ${ }^{2}$

En estas fotografías Marga enfrenta el objeto consigo mismo, tal como ella misma dice en el texto para el catálogo en 1984, "No me interesa lo estático, sino el movimiento que se produce al yuxtaponer el objeto consigo mismo, al aislarlo de su entorno o al relacionarlo con otros contextos diferentes al propio. Me interesa ese momento único y permanente que desafía a lo instantáneo. Esa continuidad de lo eterno. Esa relación principio/fin. Esa mirada propia del objeto". Con estas palabras la autora explica de una forma sutil toda la poesía que encierran sus imágenes, las cuales rezuman una poética única. Habla de las imágenes, de lo que fueron a lo que son, del antes y del después, de un momento captado y recordado, de una transformación sutil que nos lleva a un nuevo planteamiento, una nueva mirada indiscreta sobre el cambio. El objeto era y ahora será para siempre, metamorfoseado, incorrupto en su nuevo estatus.

La segunda época de la artista tiene por nombre Transformaciones, y pertenece a los años 1985-1988. Son tres años, que pueden parecer pocos para una etapa artística, pero es un tiempo de transición de una búsqueda más íntima y personal que le llevará a escribir. Marga Clark escribe poesía. Es autora de 9 libros de poesía publicados, así como libros de ensayo y de novela. Su poemario, EI olor de tu nombre, ganó el premio Villa de Madrid de poesía en 2008. Este poemario esta dedicado al igual que su novela Amarga Luz a su tía la escultora Marga Gil Roësset, que acabó con su vida a muy temprana edad.

Rafael Canogar ${ }^{3}$ dice de las obras de esta época, en el prólogo del catálogo de la exposición en la galería Juana Mordó en 1988, que son "el alfabeto con el que Marga nos da un determinado texto para comunicarnos conceptos y reflexiones sobre lo intemporal y lo sublime". Es decir, Clark crea un nuevo idioma plástico para comprender su obra, nos da las bases de su arte visual. El nuevo lenguaje se articula a través de los trípticos de imágenes, con una gradación de color que se desliza del color al blanco y el negro gradualmente, de una forma sinuosa, casi hipnótica, que mediante su contemplación nos lleva a una eterna imagen imperturbable, un locus que forma un mapa genético de los objetos que debían ser olvidados y sin embargo mediante estas obras permanecen en nuestra retina, en nuestra historia, en la perpetuidad.

Marga Clark en Transformaciones, rescata objetos que están abocados al olvido, de hecho, en la mayoría de los casos, están olvidados, pero gracias a ella dejan de permanecer en el olvido y vuelven a ser recordados en cierta forma, a vivir de nuevo en nuestra retina y en nuestro imaginario, el imaginario propio de cada uno que los contempla.

Marga Clark nos incita a "querer detener el tiempo en nuestras manos para sentirnos un poco más eternos". Nos enseña un lenguaje propio que nos lleva a recordar palabras, objetos, sentimientos.

Nos muestra con su abecedario en Transformaciones un lenguaje que evocó paulatinamente palabras. Fue la época en la que la artista fotógrafa empezaba a explorar su otro universo: la poesía. Ella misma nos asegura que la poesía es el origen de toda su creación

\footnotetext{
${ }^{2}$ GUBERN, Román. Prólogo del libro Movimiento estático, 1985, Nueva York ${ }^{3}$ CANOGAR, Rafael: [Sin título]. En CANOGAR, Rafael y CLARK, Marga: Marga Clark. Transformaciones. Madrid, Galería Juana Mordó, 1988 (s/págs.) [cat. exp.]
} 


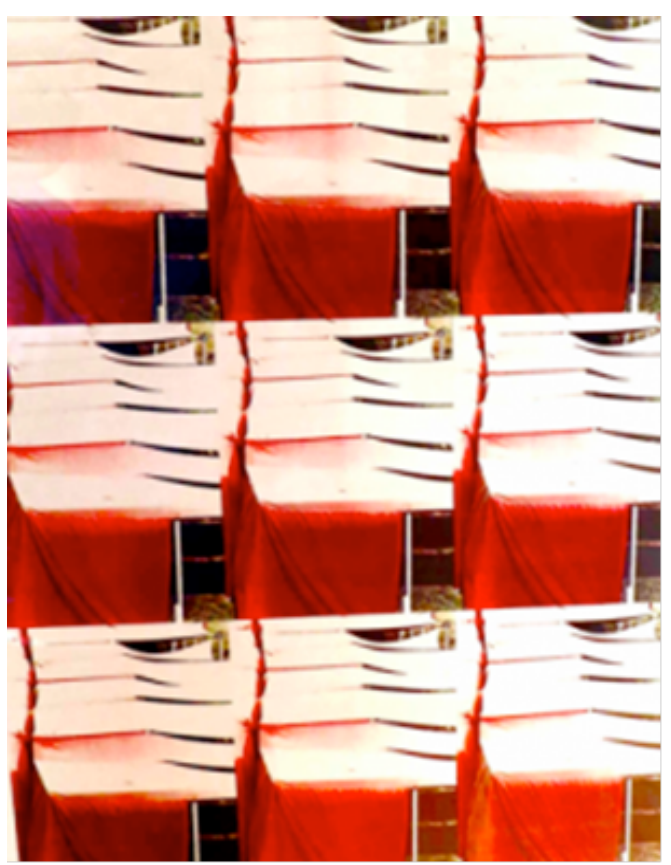

Casetas, 1985. Cibachrome.

Con respecto a Transformaciones Marga escribía en 1988:

"Nada se movía, pero todo seguía hacia adelante. La estática y el movimiento, y esa continuación perenne de las cosas que a su vez se transforman para volver a empezar una vez más. La instantánea: ese momento único de suspensión absoluta, ese querer detener el tiempo en nuestras manos, de apretarlo fuerte para sentirnos un poco más eternos. Todo se desarrollaba en el silencio, como si el transcurrir lento sólo pudiera ocurrir de esta forma. Todo, o casi todo, se sucedía esperando el momento último de permanencia donde los colores se borran y ya no existen, donde las cosas se miran ensimismadas no reconociéndose porque ya es demasiado tarde y han vuelto a ser otra vez. La mirada propia. Los ojos que contemplan los adentros, que miran la mirada. Los ojos que evocan la memoria de lo que antes era y todavía es. El conocimiento de lo que existió siempre y nunca fue del todo conocido. La pasión de ser uno mil veces multiplicado por la memoria del tiempo. La repetición abusiva de nuestros cuerpos por siempre querer ser. La necesidad de ver por primera vez"

Vemos como nos habla de la degradación, de la perdida, y de cómo para paliar y sobrellevar esa pérdida debemos ver con una nueva mirada, una mirada límpida, que reflejen Verdad, una manera de auto descubrirnos y con ello descubrir lo que nos rodea, estemos donde estemos. Es una mirada hacia el interior de todo lo que nos rodea buscando la esencia de las cosas y haciéndonos sentir que somos parte y que todo importa. Se trata de no dejar pasar en vano los momentos, que estos momentos estén vívidos en nuestras retinas. Hay que recordar que según ella: "la muerte no es el morir sino el ser olvidado".

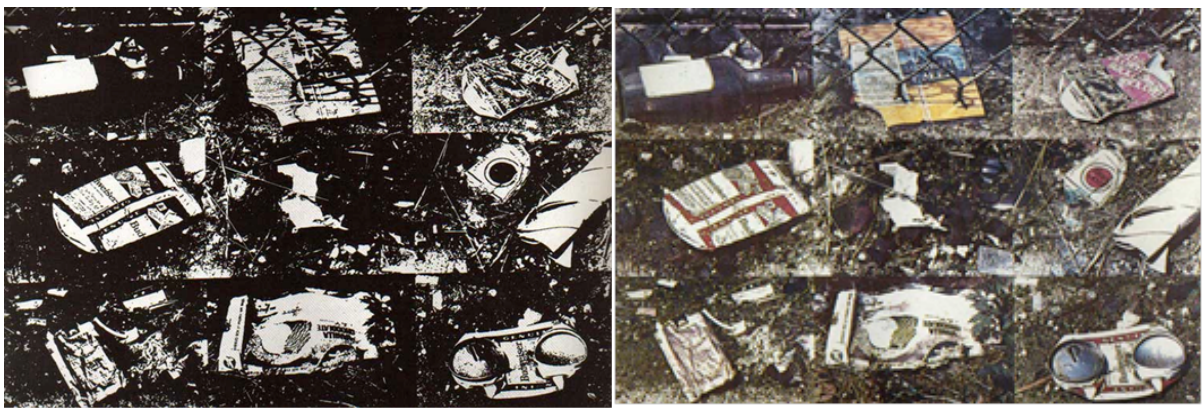

Fotografías pertenecientes a Transformaciones. 
Por último, vamos a adéntranos en la postrera época artística de nuestra creadora, Instantáneas del alma (1988-2016), la más profunda, mística y fecunda, de todas sus etapas. Desde el comienzo de su andadura artística, Marga, transita entre la vida y la muerte, aborda las contradicciones que hacen referencia a los grandes dilemas metafísicos. Primero rompiendo con la estática mediante la dinámica de la seriación, y después en su segunda etapa con la recuperación de los objetos, desechados por la sociedad, que estaban destinados al olvido y su vuelta a la memoria. En este último periodo, profundiza más en esta dualidad vida y muerte, y la materializa a través de varias obras. Son obras muchos más poéticas que las que hasta ahora hemos visto, obras de gran calado emocional que te trasponen y te llevan de forma irremediable a una atmosfera contemplativa. Componen esta etapa, sus series: Evocaciones, Cajas áureas, Cajas poéticas y arquetipos, Imágenes reveladoras, Poemas áureos y poemas traslúcidos, Miniportfolios, Habitaciones, Underground, Pasajes de la memoria, y De Profundis - Portfolio de fotografías y poemas

A través de la visión de estas imágenes, de estas obras cargadas de fuerte lirismo, es inevitable caer en el alma de la autora, que nos guía hasta ella de una forma sutil, sin aspavientos, tan solo mediantes imágenes, tomadas por ella, pero que en el fondo sentimos muy nuestras.

Marga Clark dijo tras varios años de trabajo, tanto en la fotografía como en la poesía: “Intento ir más allá de la simple apariencia de las cosas", pero debemos decir que al espectador de su obra le parece "empezar a ver por primera vez" ante la contemplación de sus obras. Sus Cajas poéticas y arquetipos, sin ir más lejos, te transportan a otro tiempo, un tiempo pasado no tan lejano, que sin embargo te hace sentir el vértigo de la fina línea que separa la vida de la muerte. Son cajas de una poesía única, conformadas por versos e imágenes que transmiten una elegancia eterna, una bucólica tranquilidad, donde la muerte y la vida se conjugan de forma sublime.

Marga Clark califica estas imágenes, de reveladoras, porque esconden en su interior la palabra poética y confiesa que su objetivo es crear "un espacio infinito de lenta contemplación". A este respecto sólo podemos afirmar que lo consigue, ya que de forma pausada te va llevando a esa contemplación sempiterna. Unos de los versos que podemos leer en estas obras son:

Te escucho porque no hablas.

Te busco porque no existes.

Te encuentro porque no eres.

El escritor Valentí Gómez-Oliver escribe en el catálogo de la exposición que la obra de Marga Clark es de carácter "trascendente" y que en las últimas décadas de su obra se ha lanzado por el intrincado camino que la llevará a captar la "invisibilidad de lo visible".

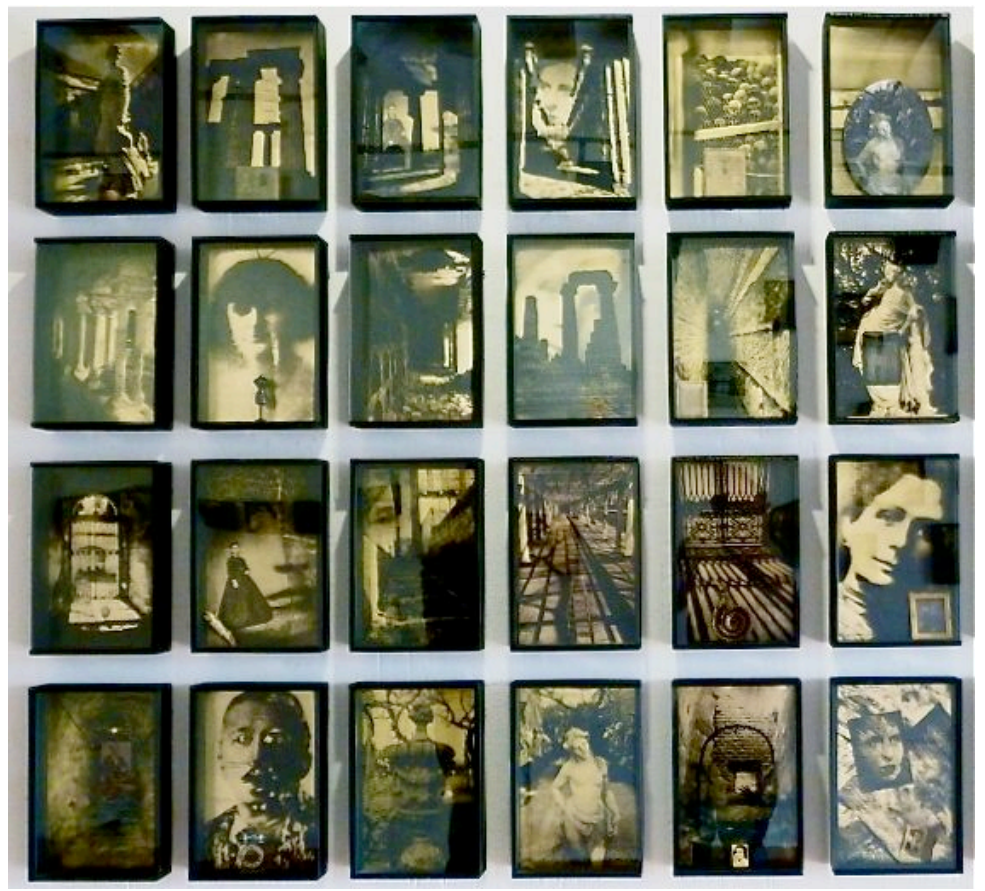

Cajas Áureas, 2016. 
Recorrer la obra de la artista es pasear por los lugares más inesperados del mundo. Un mundo en profundo cambio y adaptación, un mundo globalizado que muta constantemente, y que muta a nivel global, traspasando fronteras. Nos comenta Marga a este respecto;

"En la primavera de 1989 completé una serie de fotografías y poemas titulada De PROFUNDIS. Esta carpeta se compone de diez imágenes y diez poemas íntimamente relacionados. Los poemas fueron precursores de los rostros desvaídos que encontré en las fotografías de los nichos del cementerio San Michele en Venecia. Su incipiente estado de desintegración me impulsó a volver a fotografiar estas caras intentando parar, aunque sólo fuera temporalmente, el deterioro en la emulsión de la película consiguiendo alargar de esta forma la memoria colapsada de estos seres abandonados"A

A mi parecer la obra de esta artista no puede resumirse en este pequeño trabajo, merece un estudio más amplio, para poder apreciar los matices de su camino artístico, y de su devenir. Son cuatro décadas de una prodigiosa obra que debemos contemplar pausadamente, sintiendo cada segundo la poética que la envuelve.

La obra de esta artista visual, poeta y fotógrafa, ha sufrido una evolución paralela a la vida de la artista, lo cual es lógico, pero aunque haya evolucionado no deja de tener un hilo conductor durante toda su trayectoria. Es una obra que nos habla de Nueva York, pero en realidad podría ser cualquier ciudad del mundo. En su obra explora el cementerio de San Michele de Venecia, pero que inevitablemente nos recuerda cualquier cementerio que podemos encontrar en cualquier país del mundo, nos habla de objetos inanimados, olvidados, objetos que pueden estar olvidados en Nueva Delhi, en Japón, en Canadá o en cualquier parte del mundo. Nos habla de personas que ya no están y de las que su recuerdo está a punto de desaparecer. En el fondo nos habla de lo que es nuestro futuro, habla de la fragilidad y caducidad del cuerpo humano y del ser, de la estancia temporal en este mundo, así como de la permanencia del alma o del ente. Es una obra transfronteriza, que explica el sentimiento de todos, que une vidas cuando se admira. Una obra para tener en cuenta, contemplar y re-contemplar.

\section{FUENTES REFERENCIALES.}

CLARK, Marga. Entrevista personal realizada el 20 de enero de 2017, Madrid.

CLARK, Marga. De Profundis. Carpeta de fotografías y poemas, coedición con Carlos Manzano, Madrid, 1989.

GUBERN, Román. Prólogo del libro Movimiento estático, Nueva York, 1985.

CANOGAR, Rafael: [Sin título]. En CANOGAR, Rafael y CLARK, Marga: Marga Clark. Transformaciones. Madrid, Galería Juana Mordó, 1988 (s/págs.) [cat. exp.]

\footnotetext{
${ }^{4}$ CLARK, Marga. De Profundis. Carpeta de fotografías y poemas, coedición con Carlos Manzano, Madrid, 1989.
} 